\title{
SPORTS TRAINING - OPTIMIZING MODE OF IMPROVING THE MOTRIC CAPACITY IN PREPARATION MILITARY STUDENTS
}

\author{
Robert STĂNCIULESCU \\ “Nicolae Bălcescu” Land Forces Academy, Sibiu, Romania \\ rstanciulescu@armyacademy.ro
}

\begin{abstract}
Specialized studies show how a fighter should physically be, not just any fighter, but the one who possesses the qualities and features of the ideal model, i.e. those elements that define the nearperfect fighter. The demands of the modern battlefield impose a high quality human potential that provides a good basis for the selection and training of fighters. Resistance to physical, climate, season and weather condition demands, to the prolonged efforts fighting requires is one of the important conditions of success. The paper presents information with particular impact in optimizing exercise capacity for future officers of the land forces, emphasizing once again the idea that a high level of motric ability is an essential objective.
\end{abstract}

KEYWORDS: capacity, efficiency, physical shape, motric, optimization

\section{Introduction}

In the economy of the formative process, the high coordinates of the motric ability represent the essence of a high level of physical preparation, for which its development has been and will always remain a priority target throughout the ongoing training of military personnel. Without operating with categorical answers, it is still necessary to refer to some of the indicators that we have to address in the process of transposing the ideal model from a physical and mental point of view into a real model. From this point of view, one type of fighter that meets the requirements imposed by the war of the $3^{\text {rd }}$ millennium must be physically normal, resistant to variations in climate and weather conditions, strong and resistant to prolonged physical and mental demands.

These coordinates can be achieved through specific training methods and means directed towards improving the overall physical condition and developing resilience to stress. As the main form of training, sports training allows soldiers to maintain, even under multiple stress conditions, a high level of capacity to work and combat capability. Through sports training, one develops a large number of qualities and moral accumulations: self-control, discipline, camaraderie and willingness. \section{Content}

\section{Sports Training - Objectives and}

Sports training is a complex process, systematically, continuously and gradually carried out of adjusting the body to intense physical and mental efforts (Dragnea \& Mate-Teodorescu, 2002).

The optimization of the sports training process involves many organizational, 
medical factors, and has several features of which we highlight:

- the activity is usually carried out in an institutionalized way;

- it is based a process driven on the basis of training objectives;

- it covers a certain amount of time and hours.

Specific objectives:

- are achieved on the basis of pedagogical, biological and psychological principles and rules.

As a process, sports training is conducted in order to develop the motric capacity of the body, that is the motor skills, speed, skill, endurance and strength but also to form, consolidate and improve some basic motric and utilitarianapplicative skills.

Thus its gradual transformation is achieved by moving from one stage to another, from one set of objectives to others which imply highly complex functional, structural and psychological changes of the organism.

As a specialized process, sports training is characterized by a high specificity if we consider the type of sports discipline, the characteristics of the type of specific hard effort, and the physical attributes involved in the process of training.

From this point of view, the body adapts to the specificity of the sports discipline in a cyclical process. The cyclic processuality in which the body in motion is involved goes through the following steps (Dragnea \& Mate-Teodorescu, 2002):

- receiving information;

- retrieving information;

- decision;

- action;

- self-regulation - self-organization.

Like any organized activity, sports training involves a set of specific activities, which confers efficiency. What is meant is planning, organizing, carrying out, conducting, controlling and evaluating activities. It is conducted by following a set of principles which provide efficiency and a scientific evolution.

These are rules that guide the whole activity. There are many classifications of sports training principles but I would submit to your attention two classifications.

In 1992, Renato Manno comes with the following classification:

A. General Principles - principle of self-consciousness (motivation):

- principle of reality;

- principle of accessibility;

- principle of successfully sorting out tasks.

B. Principles of guiding the effort:

- continuity in training;

- progressivity of effort;

- multilaterality and polyvalency of training;

- cyclical alternation of training.

In 1987, Mihai Epuran makes another classification:

A. General principles:

- the principle of multilateral development of personality and of socioprofessional integration of the individual;

- the principle of efficiency and economy;

- the principle of complexity between theory and practice. of training:

$B$. Principles regarding the objectives capacity;

- maximizing the performance

- the principle of developing motor, cognitive, emotional and volitional skills;

- the principle of control;

- the principle of objectification and evaluation activities;

- the principle of collaboration between partners.

C. Principles regarding the content of training:

- principle of interdisciplinarity;

- principle of rationalisation;

- principle of operationalization.

D. Methodical-strategic principles:

- principle of individualization; 
- principle of becoming aware;

- principle of motivation and voluntary effort;

- principle of accesibility;

- principle of modeling;

- principle of stimulation;

- principle of overlearning;

- principle of specialization;

- principle of self-regulation.

\section{Means of Sports Training}

The means of sports training represent the set of practical tools used to achieve the objectives of performance (to achieve standards) that address the physical, mental and motor ability of the body.

According to Dragnea \& MateTeodorescu (2002), the means of sports training can be classified as follows:

- means of training or lesson; capacity;

- means of rebuilding the effort

- competitional means;

- the means of training or lesson represent the ensemble of physical exercises ensuring transformations and improvements at different levels.

They can be divided as follows (Dragnea \& Mate-Teodorescu, 2002):

a. means of general training;

b. means having a mixed character;

c. means of specific training.

a. The means of general training are extremely important and, in our opinion, they represent the basis of the training system as they provide the normal development and functioning of the body.

Usually in their choice one should consider the following aspects: of trainees;

- to foster multilateral development

- to develop the basic motor skills;

- to enlarge the set of motion skills and aptitudes;

- to reflect the peculiarities of the body. b. The means having a mixed or specific character exercises are at the borderline between the general and the specific exercises and often ensure the passage from one to another.

c. The means having a specific character belong to different sports disciplines and are employed to improve the utilitarian-applicative qualities and skills specific to them.

This type of exercises can be of two kinds: of approaching, contributing to acquiring the technique of movements and of development, being oriented towards the proper development of the exercise capacity.

\section{Means of rebuilding the capacity to exercise \\ Many specialists in the field} emphasize the vital role of restoring the body after exercise. Recovery after exercise is essential to progress.

Without a full recovery after exercise, high performance results cannot be obtained as the training exercises cannot be fully carried out and at the right intensity.

Restoration is a component of sports training using rationally and in a guided manner a number of natural and /or artificial medical and pedagogical means coming from the external and /or internal environment of the body in order to restore the functional hemeostazy, the effort, especially to overcome it by FUNCTIONAL OVERCOMPENSATION (Dragnea, 1996).

The efforts put into training require a rapid restoration of physical and mental capacities so that, after a certain period of time, the body is able to work at full and complete physical and psychic capacity.

In 1987, Mihai Epuran says that the means used in recovery are divided into specific means, which are conducted in medical terms and non-specific that can be applied by the coach or trainee.

A particularly important role in the recovery after effort is played by the 
psychological means which ensure an environment favorable to amplifying the effects of physical exercises.

Adrian Constantin Dragnea \& MateSilvia Teodorescu (2002) stress that the means of psychological preparation constitute the instruments directly used in the workout, contributing to optimizing the mental states with favorable effects on the state of performance.

The means of recovery after exercise influence certain body functions and systems, creating optimal conditions for the resumption of effort. These are:

- means that accelerate neuropsychic recovery (active rest, massage, hydrotherapy, medication, etc.);

- mijloace neuromuscular recovery (active rest, medication, diet, etc.);

- means that accelerate endocrinometabolical recovery;

- means that accelerate cardiorespiratory recovery.

\section{$>$ Competitional means}

They have an integrative character and different contents from one sports discipline to another. They can be used singularly in the lesson or combined with other means, depending on the objectives proposed in the respective stage.

\section{Means of Sports Training}

In sports training, the methods used are common with those used in physical education. However, there are different characteristics drawn from the various organizational conditions, leading to slight differences between them.

Thus, one type of methods is based on the EFFORT - REST relationship, in which the essence is represented by the way the body manages to harmonize this type of relationship. The effort may be standard or variable, continuous or with breaks, while rest can be active when the body recovery is done by executing various mild or passive activities, when the natural recovery of the body is expected, i.e. return to the state before effort, without running this type of activity.

The methods used depend on the intensity, volume and complexity of the effort required to obtain an adjustment in the desired direction and their association with different types of breaks. Another type of methods is based on the PART WHOLE relationship.

From this point of view, we highlight the method of modeling.

Modeling supposes the elaboration of a model and has a methodological function provided by the following aspects:

- increased frequency of use of the method compared with other methods;

- transition from experimental discovery of the particular in building models regarding the general;

- transition to the global study on the model.

In these circumstances modeling involves a system of operations that provide information carried out under a scheme offering efficiency.

Here are the requirements of a model, according to Mihai Golu in 1975:

- to be relevant;

- to be simple;

- to be isomorph;

- to have a generalized character.

\section{Lesson}

5. Structure of Sports Training

In the field of sports training, we frequently use the term sports training lesson, which is a system of stimuli designed specifically to produce some changes on the body, which are qualitative and quantitative transformations.

It is a well organized process with clear objectives that involve applying work strategies different from one stage to another.

As an organizational structure, the sports training lesson is made up of three parts:

a. The introductory material includes organizational aspects, working conditions, 
specifications regarding the content of the activity and the preparation of the body for effort. It can certainly be standardized or individualized. Depending on the type of objectives or the structure of the sports training lesson, preparing the body for exercise can be done at different levels of intensity or duration. It can also vary depending on the climate and temperature or weather conditions where it takes place, as well as depending on the specific sports discipline.

Its importance is crucial as it prepares the body, that is the osteo-articular system and the major functions of the body (circulation or breathing function), for the effort that the body will undertake.

A proper preparation of the body for exercise reduces the risk of accidents of any kind and increases efficiency for obtaining performance.

b. The fundamental or training part in which the objective or objectives of the lesson are achieved. A limitless set of specific and non-specific means or methods can certainly be used in this part of the lesson, aimed at improving certain motor, as well as specific skills. The technical or tactical elements are made efficient, the psychological component is worked on, or the objectives specific to different components of the preparation are combined.

c. The closing (or final) part returns the body and the major functions to the state of effort through walking and mild jogging exercises, breathing or gymnastics exercises.

It is important because it slowly makes the transition from one state to another, managing to harmonize the body states. A number of specific issues can be sorted out in this part of the lesson, relating to achieving objectives, plans for future training or psychological preparation elements, as well as recommendations of the coach on the tasks to be achieved in their free time.

There many types of sports training lessons, each author producing a certain type of hierarchy.

In their program, the forming, strengthening or improving of several components of sports training (the four types of technical, tactical, physical and psychological training) are aimed at, as well as the verification lessons, which we consider to be the best form of training.

\section{Conclusions}

Sports training systematically and continuously conducted increases the action capacity because it strengthens muscles, enhances the elasticity of joints, improves reflexes and ensures the physical and moral balance. The effect of physical exercises is also manifested by the possibility that the military gains, to act spontaneously and in a relaxed manner. Psychologically, physical training frees man from the nervous tendency, from conflict between thought and action. Physical training is not intended to lead to the simplistic acquisition of a method of struggle, but to develop the skill of intuitively synchronizing actions in every situation, so that the action becomes identical with the mission to be fulfilled. It is therefore necessary to take account of the impact the battlefield has on the physical and mental part of the body in order to identify the most effective methods of training the body.

\section{REFERENCES}

Dragnea, A. (1996). Antrenamentul sportiv. Bucureşti: Didactică şi Pedagogică. Dragnea, A. \& Mate-Teodorescu, S. (2002) Teoria sportului. Bucureşti: Fest. Epuran, M. (1987). Psihologia educaţiei fizice, vol. III. Bucureşti: Reeditarea. Golu, M. (1975). Principii de psihologie cibernetică. Bucureşti: Didactică şi Pedagogică. Manno, R. (1992). Les bases de l'entrainement sportif, Edition revue. Paris: E.P.S. 